\title{
EL FUNDAMENTO \\ DE LA DEMOCRACIA EN LA OBRA \\ DE ELÍAS DÍAZ
}

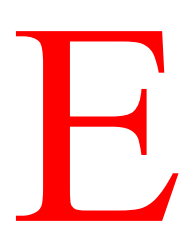

1 término que con más acierto define la personalidad de Elías Díaz es, sin duda, el de demócrata. Tanto su producción intelectual, como su biografía personal, atestiguan que la lucha por la democracia ha sido en él una pasión arraigada y permanente. Y ello tanto contra las dictaduras de uno y otro signo, como contra el riesgo de un individualismo extremo, propenso a inmunizar excesivamente al individuo contra el poder de decisión de las mayorías. Y digo la democracia más que el socialismo porque el socialismo, para Elías Díaz, es impensable sin la democracia. Más aún, el socialismo, bien entendido, resulta a la postre idéntico con la democracia, siempre que ésta no sea vaciada de significado al hacerla coincidir con unos mínimos procedimientos formales de decisión sin los imprescindibles referentes económico-sociales.

Ha sido la suya una pasión contra el franquismo. Él es uno de los que supieron defender con los mejores argumentos filosófico-jurídicos el Estado democrático en nuestro país en tiempos de la dictadura. Su libro Estado de derecho y sociedad democrática (Madrid, 1966) ha inspirado la teoría y la práctica de varias generaciones de españoles. Ha sido también una pasión contra el marxismo de cuño leninista, tendente a ignorar la virtualidad de las instituciones del Estado representativo y a abandonar las libertades democráticas en el proceso de construcción del socialismo. Su libro De la maldad estatal y la soberanía popular (Madrid, 1984), si bien continúa defendiendo la racionalidad del Estado democrático frente a posiciones iusnaturalistas que mantienen una idea de la justicia sustraída a las decisiones políticas, amplía sus objetivos apuntando hacia la izquierda para afirmar la necesidad de la democracia en el empeño de construir una sociedad más libre y solidaria. Y ha sido una pasión contra un individualismo de corte ácrata o elitista, que le ha salido al paso en su defensa de una concepción democrática (política) 
de la legitimidad con el estandarte de la ética kantiana, y al que ha tenido que enfrentarse afinando sus argumentos acerca de una teoría crítica de la justicia, en la que la democracia y la regla de la mayoría siguen jugando un papel imprescindible. En esta ocasión, su libro Ética contra política. Los intelectuales y el poder (Madrid, 1990) contiene, junto a posiciones antiguas, una renovada insistencia en conectar la política con la ética, en dotar a la política (democrática) de valor ético, y en dotar a la ética de connotaciones explícitamente democráticas.

Defender la democracia contra formas autoritarias de organización política puede parecer fácil. Las razones de la democracia contra las dictaduras políticas son, en las sociedades avanzadas, generalmente convincentes, al menos las razones de orden práctico que ponen de relieve las ventajas que para el bienestar del individuo y el progreso económico-social representa un régimen político pluralista y dinámico, que aprovecha mejor que ningún otro las potencialidades sociales, y que resuelve los conflictos y se renueva con normalidad fisiológica. A pesar de la tesis de la ingobernabilidad de las sociedades democráticas, se reconoce el potencial estabilizador de los procesos de decisión política de carácter representativo, en los que la participación popular mediada a través de multitud de mecanismos, y los controles formales e informales de la acción de gobierno aseguran la lealtad de las masas y la reproducción del sistema. En definitiva, se reconoce normalmente la capacidad de la democracia para dotar de legitimación al orden jurídico-político existente.

No son tan convincentes, en cambio, las razones éticas de la democracia, y defenderla como una instancia de legitimidad, cuyas decisiones son moralmente vinculantes, es una tarea ardua que exige rebatir las pretensiones siempre reiteradas de una idea objetiva de justicia, sea bajo el ropaje de una u otra filosofía acerca de los valores que valen incondicionalmente, sea bajo el ropaje de un liberalismo exacerbado, que exalta los derechos del individuo como un límite inexpugnable e inaccesible a la soberanía popular.

Conjugar la democracia con los valores, y, sobre todo, con la libertad individual, es el eterno problema de la teoría (y de la práctica) democráticas. Elías Díaz aborda este problema de manera resuelta y decidida, y aunque no responde a la infinidad de cuestiones que encierra, sí que nos ha enseñado -y no es poco- a plantearlo correctamente a fin de poder enmarcar y resolver de manera plausible la multitud de sus aspectos. Me gustaría poner de relieve cómo intenta superar las dificultades que toda teoría de la democracia presenta para la legitimidad del derecho, fundamentalmente la tensión entre la soberanía popular y la defensa de unos valores o derechos fundamentales que para muchos son la base incuestionable de la legitimidad jurídica. 


\section{I}

Es frecuente oponer a una concepción de la legitimidad del poder vinculada a su origen, una concepción distinta de la legitimidad, acreditada mediante su ejercicio. En el trasfondo de esta oposición se encuentra la creencia en una idea objetiva de la moralidad y de la justicia, independiente de las decisiones y de las representaciones humanas. En el contractualismo clásico podemos observar el desarrollo de esta doble concepción de la legitimidad. Los clásicos estaban convencidos de que la soberanía popular era el camino más directo hacia la justicia, pero no todos coincidían en la manera de emprender ese camino. Los iusnaturalistas creían que la naturaleza señalaba los preceptos que había que seguir para actuar justamente, y creían también que la razón, sin prejuicios, podía descubrirlos. Naturaleza y razón son los pivotes sobre los que gira toda la construcción del iusnaturalismo clásico. Si la justicia es dar a cada uno sus derechos, basta con asegurar que la ley los consagre como derechos efectivamente vinculantes e inalienables, y que el poder público quede sometido a los suficientes controles para garantizar que no cometerá abusos o que éstos serán castigados. Así, en Locke la legitimidad de origen queda sometida a la legitimidad de ejercicio. El consentimiento que prestan los ciudadanos al gobierno se encuentra encaminado a asegurar el disfrute de los derechos que poseen como hombres en el estado de naturaleza. Por ello el poder legislativo está sometido a las restricciones procedentes de la ley natural. El Estado es antes un Estado de derecho que un Estado democrático. La fragmentación del poder, la posibilidad de su revocación por parte del pueblo, la representación política, etc., son las mejores cautelas que pueden instaurarse para asegurar la justicia natural.

En Rousseau, en cambio, ya no se trata tanto de garantizar que las leyes reflejen la justicia natural (al menos en el Rousseau del Contrato social) como de hacer que en el estado social la voluntad de todos se oriente hacia el interés general convirtiéndose en voluntad general. La legitimidad de origen es al mismo tiempo legitimidad de ejercicio. La voluntad general es, por definición, justa, porque por definición refleja el interés general de la sociedad. Claro que esto no ocurre incondicionalmente, porque para que dicha voluntad general surja han de darse determinadas circunstancias (el amor a la patria, el interés por los asuntos públicos, la igualdad entre los ciudadanos). Pero propiamente no hay límites incuestionables que la voluntad general no pueda tocar. No hay dogmas ni valores superiores que puedan oponérsele. Lo que goza de validez incondicionada es la voluntad misma como manifestación de la libertad ejercida en común. 
Basten estas breves alusiones para recordar cómo la lógica liberal es distinta de la lógica democrática. El liberalismo se ha preocupado siempre de mantener a salvo los derechos individuales como garantías para la salvaguarda de un ámbito privado, previo a la constitución del Estado y a salvo de la decisión de los demás, considerada como amenazadora y potencialmente opresiva. J. S. Mill, en la línea de Locke, concibe las libertades como un baluarte para la defensa del individuo contra las posibles injerencias de la sociedad. Lo que se ha dado en llamar libertad negativa es anterior a la libertad positiva, los derechos del individuo son previos a los derechos del ciudadano. Por eso la participación política es secundaria y encuentra siempre el muro infranqueable de los derechos naturales del hombre.

Hoy día los derechos naturales del hombre se han convertido en derechos humanos, derechos morales, o simplemente derechos. Estos siguen concibiéndose frecuentemente como atributos del individuo independientes del Estado, cuya garantía en forma de derechos subjetivos dotaría de legitimidad al orden jurídico y serviría para limitar y controlar la acción del poder, incluso la del poder democrático.

Entre nosotros esta postura está representada, de forma característica, por Eusebio Fernández. Eusebio Fernández entiende que la legitimidad del orden jurídico-político tiene un doble fundamento: contractual y iusnaturalista, o democrático y moral. Según él, el hecho de que los ciudadanos, directa o indirectamente, presten su consentimiento a las leyes no las hace $\sin$ más justas. Es preciso que quien elabora las leyes respete los contenidos vinculantes representados por los derechos humanos fundamentales. Estos derechos, de carácter moral, son previos al sistema democrático y tienen "prioridad axiológica» sobre la democracia $^{1}$. La democracia es una condición necesaria de la legitimidad, pero no es una condición suficiente de ella. Es una condición necesaria porque, sobre todo, expresa el respeto de «los valores y principios éticos de autonomía individual, libertad e igualdad» ${ }^{2}$, siendo por eso mismo un «hecho moral»; y, además, porque es el marco que sirve, mejor que ninguna otra alternativa, «para articular, regular y modelar en instituciones sociales, políticas y jurídicas esos principios y valores de una forma racional y universalizable» ${ }^{3}$. Pero no es una condición suficiente porque no todas las decisiones colectivas que se producen con base en esa autonomía individual, libertad e igualdad son forzosamente justas. Así, sería injusta

${ }^{1}$ La obediencia al Derecho, Madrid, Ed. Civitas, 1987, pág. 176.

${ }^{2}$ Teoría de la justicia y derechos humanos, Madrid, Ed. Debate, 1984, pág. 198. La obediencia al derecho, cit., pág. 138.

${ }^{3}$ Teoría de la justicia y derechos humanos, cit., pág. 199. La obediencia al derecho, cit., pág. 139. 
cualquier decisión democrática que atentase contra los «derechos morales» de las personas. A su vez, el fundamento de tales derechos morales, o derechos humanos, «debe ser buscado en los valores morales que los justifican y sirven para reivindicarlos, los cuales responden y son una «abstracción» (si se me permite el término) de una dimensión antropológica básica, constituida por las necesidades humanas más fundamentales y radicales para una existencia digna $\gg^{4}$.

No puedo realizar en este contexto otras precisiones que serían necesarias para calibrar en toda su amplitud el sentido de estas afirmaciones. Sin embargo, lo que me interesa destacar es que aquí asistimos a una duplicidad innecesaria del principio de legitimidad. Si legítima es una decisión que merece el reconocimiento de todos los afectados por ella, no hay nada legítimo previamente al proceso en el que se dilucida si algo es merecedor de reconocimiento. Con anterioridad a ese proceso sólo puede haber propuestas más o menos personales o subjetivas, que sólo adquirirán la condición de legítimas cuando se acrediten como merecedoras de reconocimiento general. La democracia no es otra cosa sino ese proceso intersubjetivo de debate y decisión acerca de lo que merece reconocimiento. Por eso la democracia es la única fuente de legitimidad ${ }^{5}$.

Desde este punto de vista, se puede estar de acuerdo en que los derechos limitan la democracia, pero en cuanto derechos democráticos, es decir, como una consecuencia lógica de la aceptación del principio democrático, ya que son el presupuesto imprescindible para una realización equitativa, genuina o auténtica, de ese proceso intersubjetivo de debate y decisión acerca de los asuntos de interés general en que consiste la democracia. Ésta no puede entenderse simplemente como el mejor marco para la realización de los derechos humanos, de unos derechos humanos previos anclados en una

${ }^{4}$ Estudios de ética jurídica, Madrid, Ed. Debate, 1990, pág. 68. El fundamento de los derechos humanos en las necesidades es compartido por muchos. Con ello se pretende superar el idealismo de ciertas propuestas fundamentadoras basadas en una filosofía de los valores de carácter intuitivo. Véase el documentado libro de A. E. Pérez Luño: Derechos humanos, Estado de derecho y Constitución, Madrid, Ed. Tecnos, 1986 (2. ${ }^{\mathrm{a}}$ ed.) esp. págs. 132 y ss. Pérez Luño propugna, a su vez, una fundamentación de los derechos humanos «a partir de la experiencia de las necesidades humanas», que para él es una experiencia mediada intersubjetivamente. Un panorama sobre la concepción del fundamento de los derechos humanos en nuestro país lo ofrece el volumen de J. Muguerza y otros: $E l$ fundamento de los derechos humanos, Madrid, Ed. Debate, 1989. Más recientemente, sobre la relación entre las necesidades y los derechos, ver M. ${ }^{a}$ José Añón Roig: Necesidades y derechos. Un ensayo de fundamentación, Madrid, C. E. C., 1994.

${ }^{5}$ Roberto Vernengo advierte en Eusebio Fernández un dualismo típicamente platónico, en el que percibe (quizá exageradamente) consecuencias políticas fatales para la democracia ( «Los derechos humanos y sus fundamentos éticos», en J. Muguerza y otros: El fundamento de los derechos humanos, cit., págs. 327 y ss.). 
concepción objetiva de la naturaleza humana. Ninguna idea acerca de las necesidades humanas que deben ser satisfechas, o acerca de los intereses que deben ser atendibles, puede valer incondicionalmente fuera de lo que resulte aceptable por parte de todos los que manifiesten necesidades o aleguen intereses.

Puede haber derechos que se consideren fundamentales como resultado del debate en torno a necesidades básicas o intereses vitales, es decir, como cristalización del acuerdo al que lleguen los afectados en un momento dado, y que, obviamente, tendrán un carácter contingente y variable en función de las circunstancias históricas en que se produzca el debate y el acuerdo. Pero más importantes que esos derechos son aquéllos que deben ser forzosamente aceptados con la aceptación del principio de legitimidad democrática. Esta última categoría de derechos, ni vienen dados a priori por una u otra concepción de la naturaleza humana, ni tampoco son dependientes de una decisión adoptada intersubjetivamente a lo largo de la historia. Más bien son estructural y funcionalmente necesarios desde el punto de vista de la democracia, cuyo sentido coincidiría precisamente con el respeto de tales derechos.

Esto es lo que ha sabido ver Elías Díaz. En su defensa del principio de legitimidad democrática, Elías Díaz tiene que rebatir las objeciones de los que alegan que por encima de la soberanía popular y del criterio de decisión por mayoría, existe un «prius» axiológico que vincularía objetivamente la decisión de la voluntad humana y le asignaría unos límites infranqueables. Resumiendo sus argumentaciones, dice literalmente: «Por su propia lógica interna, la regla de decisión de las mayorías, incluso convertida en ley, no puede, entre otras cosas: a) ni suprimir físicamente al discrepante (o al no discrepante); b) ni prohibir la libertad crítica y de pública expresión de ideas, opiniones y juicios; c) ni negar a los ciudadanos la participación política en comicios y libres periódicas elecciones. Al contrario, deberá potenciar muy positivamente tales cualidades y libertades. Repito, éstas básicamente -con diferente calificación-, y d) otras exigencias a ellas íntimamente vinculadas -seguridad, paz, igualdad, etc.- no constituyen un «prius» ni un límite que se imponga desde fuera a la soberanía popular; constituyen exigencias lógicas internas de la regla de decisión mayoritaria, de la soberanía popular y de la propia legitimidad democrática. Y de ellas derivan, con ese mismo carácter, e) otros importantes derechos fundamentales que forman parte y dan pleno sentido a lo que hoy sería una teoría crítica de la justicia» ${ }^{6}$.

${ }^{6}$ De la maldad estatal y la soberanía popular, Madrid, Ed. Debate, 1984, pág, 142, subrayado mío. Véase también, en este mismo sentido, Luis Prieto: «La democracia es un 'prius' sin el que resulta inviable plantearse siquiera la virtualidad de 
Por supuesto, la institucionalización de los procedimientos y criterios de debate y decisión democráticos no cancela la pregunta por la justicia. Siempre es posible, en el seno de una sociedad y de un Estado aceptables generalmente por su carácter democrático, cuestionar la justicia de una acción o de una norma. Las decisiones de una determinada democracia política pueden ser calificadas como injustas. Ahora bien, no desde una concepción de la justicia situada fuera del debate y de la decisión humanas. Si se pretende huir de una concepción dogmática de la justicia, ésta sólo puede ser entendida como el resultado de un proceso de decisión idealmente democrático, en el que se llegase a un acuerdo suscrito por todos los potencialmente afectados. De esta forma, se puede decir que una decisión adoptada en unas determinadas instituciones democráticas es injusta por ser insuficientemente democrática, es decir, por haber sido adoptada sin la participación equitativa (en libertad e igualdad) de todos los afectados o de aquellos que hayan podido defender equitativamente sus intereses. De nuevo, Elías Díaz: «Habría, por de pronto, que señalar que la justicia, y algunas razones válidas para ella, encuentran su más firme apoyatura y hasta fundamento precisamente en la constatación de las insuficiencias que en la realización de esos proclamados valores de libertad e igualdad se muestran con gran frecuencia en los concretos sistemas históricos de legalidad y de legitimidad, incluido, por supuesto -aunque sea el mejor de ellos-, en el de carácter democrático» ${ }^{7}$.

Quien pretenda convencer a otros de la injusticia de una decisión tendría que demostrar en principio que tal decisión no habría sido adoptada por un observador imparcial que tuviese un conocimiento suficiente de las necesidades e intereses en litigio. Lo cual equivale a demostrar que no habría sido adoptada si todos los afectados hubiesen podido intervenir públicamente con argumentos a favor o en contra de ella, en plenas condiciones de libertad e igualdad. Se supone que en tales condiciones sólo se impondrían las mejores razones, y no prosperarían los intereses privativos de nadie. Pero como demostrar tal cosa es imposible, la afirmación de la injusticia de una decisión sólo podrá hacerse a título hipotético, de la misma manera que sólo puede hacerse a título hipotético la afirmación de que un

los derechos, y las libertades representan una condición de la existencia misma de la democracia. No es que sean anteriores en el sentido iusnaturalista, sino que se hallan en la estructura de todo posible consenso, como creo que confirma la propia experiencia histórica» («Ideología liberal y fundamentación iusnaturalista de los derechos humanos. Observaciones críticas», en Anuario de Derechos Humanos, nº 4, 1987, págs. 291 y ss., pág. 311).

${ }^{7}$ Ética contra política. Los intelectuales y el poder, Madrid, Centro de Estudios Constitucionales, 1990, pág. 54. 
observador imparcial habría adoptado una decisión diferente a la que se reprueba como injusta.

Sin embargo, siempre es posible señalar las deficiencias concretas que lastran los procedimientos políticos de debate y decisión, cuando se han institucionalizado históricamente. Esto es lo que no puede hacer ninguna decisión, por muy mayoritaria o unánime que sea: vulnerar las condiciones estructurales de los procedimientos democráticos de decisión. Tales condiciones estructurales no deben entenderse en un sentido estrecho, sino que incluyen todos aquellos factores que hacen que todos los afectados por una decisión puedan participar con igual autonomía en su justificación. Esos factores se dan tanto en el ámbito de la vida política como en el ámbito de la vida social, tanto en la esfera pública como en la esfera privada, tanto en lo que afecta al ciudadano, como en lo que afecta al individuo. Por eso el catálogo de los derechos democráticos es amplio, y su justificación como derechos fundamentales no queda limitada a los que posibilitan la participación política en sentido estricto. «Pero yo no veo a la libertad negativa escindida de la libertad positiva. Sin dejar de reconocer la necesidad de otras posteriores concreciones, lo que quiero ahora resaltar es que la zona donde los otros no pueden, no deben, entrar (libertad negativa) deriva y debe sustancialmente derivar, coincide más bien, con la misma raíz de la que procede la autonomía de la voluntad individual (libertad positiva): es decir, la dignidad ética de la persona, o como quiera llamársele, la autonomía moral, el factor diferencial del ser humano (razón, voluntad, libertad), la capacidad de autoconciencia (relativa, desde luego) y la consiguiente necesidad de decidir por uno mismo y todos juntos por la colectividad» ${ }^{8}$.

Es esta una concepción análoga a la sostenida por J. Habermas, quien afirma que ambos tipos de derechos, los de la autonomía pública y los de la autonomía privada, son cooriginales y de igual peso. Y lo son porque ambos son esenciales para el proceso político democrático. También para él existe una conexión interna entre la soberanía popular y los derechos humanos, consistente en el hecho de que los derechos humanos proporcionan precisamente las condiciones bajo las cuales pueden ser institucionalizadas legalmente las diferentes formas de comunicación necesarias para una creación del derecho políticamente autónoma. Estas condiciones no son restricciones a la soberanía popular, sino precisamente condiciones que hacen posible su ejercicio: «La substancia de los derechos humanos reside en las condiciones formales para la institucionalización jurídica de aquellos procesos discursivos de formación de la opinión y de

${ }^{8}$ Ética contra política, cit., págs. 42-43. 
la voluntad en los que la soberanía del pueblo adquiere forma jurídica» ${ }^{9}$.

Con base en todos estos argumentos es como Elías Díaz conecta la política con la ética: a través de la conexión entre una concepción democrática de la legitimidad y una teoría también democrática de la justicia. La legitimidad, que es un concepto político, se prolonga en la justicia, que es un concepto ético. La política se prolonga en la ética, y tiene que acreditarse finalmente en ella, pero la ética no puede ser concebida si no es con una naturaleza intersubjetiva, discursiva $\mathrm{o}$, lo que es lo mismo, genuinamente democrática ${ }^{10}$.

En esta misma línea, hablar de «Estado democrático de derecho» no es más que expresar una redundancia. No puede haber democracia sin derechos, ni derechos sin democracia. Es decir, no puede organizarse un procedimiento de debate y decisión en el que intervengan todos los afectados, si no se asegura su participación o representación a través de la institucionalización de los correspondientes derechos y libertades. Y no se pueden institucionalizar derechos que no sean el resultado final o el requisito previo de tal procedimiento.

Luigi Ferrajoli ha elaborado una articulación del Estado democrático de derecho en la que disocia ambos elementos en una doble concepción, procedimental y sustancial, del Estado legítimo. Su versión del garantismo en Diritto e ragione prolonga la tradición iusnaturalista y contractualista del liberalismo clásico. Para Ferrajoli el garantismo proporciona las nociones claves para asegurar la protección de los bienes e intereses básicos de las personas. En su interpretación liberal, estos bienes o intereses tienen un carácter prejurídico y externo al orden estatal, aunque a diferencia del iusnaturalismo clásico son convencionales e históricamente variables. Pero constituyen la razón de ser del Estado, justifican su existencia y orientan su actividad. Su consagración en el ordenamiento jurídico como derechos fundamentales permite hablar de Estado de derecho. «Está claro que una vez reconocida su naturaleza de principios axiológicos de justificación del Estado, ellos no son fundados, sino fundantes; pero lo son no ya en cuanto normas o, lo que es peor, en cuanto situaciones de derecho natural, sino precisamente en cuanto principios ético-políticos externos, privados de fundamentos porque ellos mismos son fundamentos y fruto no de normas jurídicas, sino de opciones o convenciones» ${ }^{11}$.

${ }^{9}$ Faktizität und Geltung, Francfort, Ed. Suhrkamp, 1992, pág. 135. También, casi con el mismo tenor literal, en «Human Rights and Popular Sovereignty: The Liberal and Republican Versions», en Ratio Iuris, vol. 7, nº 1, 1994, págs. 1 y ss., pág. 13.

${ }^{10}$ Ética contra política, cit., págs. 17 y ss.

${ }^{11}$ Diritto e ragione. Teoria del garantisino penale, Roma-Bari, Ed. Laterza. 1989, pág. 957. 
Hay una diferencia entre Estado de derecho y democracia política. La democracia hace referencia al origen y al procedimiento de las decisiones, a la pregunta sobre quién puede y cómo se debe decidir. El Estado de derecho hace referencia, en cambio, a la pregunta acerca de qué cosa se debe o no se debe decidir ${ }^{12}$. En este sentido, los derechos aparecen como un sistema de límites sustanciales de la soberanía popular, precedentes no sólo cronológicamente, sino también axiológicamente a la democracia. «Incluso la democracia política más perfecta, representativa o directa, es en efecto un régimen absoluto y totalitario si el poder del pueblo es ilimitado. Sus reglas son sin duda las mejores para determinar quién puede decidir y cómo debe decidir, pero no bastan para legitimar cualquier decisión o no decisión. Ni siquiera por unanimidad puede un pueblo decidir (o consentir que se decida) que un hombre muera o sea privado sin culpa de su libertad, que piense o escriba o no piense o no escriba de una determinada manera, que no se reúna o no se asocie con otros, que se case o no se case con una determinada persona o quede ligado a ella indisolublemente, que tenga o no tenga hijos, que haga o no haga tal trabajo, $u$ otras cosas semejantes ${ }^{13}$.

Ferrajoli redefine el Estado de derecho dotado de efectivas garantías como una democracia sustancial, mientras que el aspecto procedimental y representativo del Estado es designado por él como democracia formal. Democracia sustancial en cuanto que posee normas relativas al contenido sustancial de las decisiones, normas que establecen cuáles son los intereses y necesidades vitales de las personas y a los cuales está subordinado el poder político. Y democracia formal en cuanto que posee normas relativas al origen y procedimiento de tales decisiones, normas que aseguran la representatividad de las fuentes y de las formas de decisión. "Sobre el plano lógico los dos modelos de democracia son obviamente independientes, [...] y es también claro, sobre el plano axiológico, que la democracia sustancial incorpora valores más importantes, y en cierto modo prejudiciales, respecto de la democracia formal» ${ }^{14}$.

Me parece que tiene razón Michelangelo Bovero cuando cuestiona la filosofía política subyacente a esta duplicidad del concepto de democracia. Creo que las distinciones de Ferrajoli son operativas y fructíferas desde el punto de vista de una dogmática jurídica que se toma en serio la defensa del individuo contra el poder legal del Estado. Su concepción del garantismo le suministra al jurista comprometido con la crítica del poder los criterios conceptuales necesarios

\footnotetext{
${ }^{12}$ Op. cit., pág. 898.

${ }^{13}$ Op. cit., pág. 900.

${ }^{14}$ Op. cit., pág. 906.
} 
para denunciar los abusos desde el interior del sistema jurídico. Le suministra también a la jurisdicción comprometida con las libertades ciertas nociones teórico-jurídicas justificativas de una actuación política liberal legalmente irreprochable. Sin embargo, el problema reside en el fundamento de esos derechos o garantías que limitan sustancialmente las decisiones políticas y que constituyen el núcleo de significado de un concepto de democracia sustancial. ¿Cuál es para Ferrajoli el fundamento de esas garantías fundamentadoras del Estado democrático? Una noción histórica de las necesidades y los intereses primarios de las personas. Dice M. Bovero: «Yo no creo que la democracia tenga que ver con el «qué cosa» de las decisiones colectivas, o sea, no creo que sea posible establecer (o medir) la democracia de una decisión sobre la base de su contenido; como no creo que sea muy fácil establecer cuáles son 'las necesidades o intereses primarios de todos', ni que sea lícito -y mucho menos democrático- intentar establecerlo independientemente de las opiniones manifiestamente expresadas por los mismos individuos en el proceso democrático formal. No sé si cada uno es el mejor juez de su propio interés, pero ciertamente es, desde el punto de vista democrático, el único intérprete autorizado» ${ }^{15}$.

También aquí se corre el riesgo que conlleva una definición de los derechos previa e independiente del proceso democrático. Aunque, como afirma Ferrajoli contra el iusnaturalismo y apelando a Norberto Bobbio en este aspecto, los derechos se establecen convencionalmente en el transcurso histórico ${ }^{16}$. Ahora bien, si esos derechos limitadores de las decisiones democráticas, sobre los que no cabe el poder de disposición de la soberanía popular, no han sido blindados de manera iusnaturalista como derechos innatos, entonces es que han sido blindados como convenciones históricas que no tienen más valor que el de las mayorías que los han establecido. Según Ferrajoli, los derechos fundamentales son establecidos efectivamente «en aquellos contratos sociales en forma escrita que son las cartas constitucionales, sólidamente emanadas de mayorías cualificadas», pero lo que distingue al Estado constitucional de derecho es precisamente que «esos derechos y principios valen 'independientemente de las opiniones manifiestamente expresadas en el proceso democrático formal', o sea independientemente de la voluntad de la mayoría» ${ }^{17}$.

15 «La filosofía política di Ferrajoli», en L. Gianformaggio (a cura di): Le ragioni del garantismo. Discutendo con Luigi Ferrajoli, Turín, Ed. Giapichelli, 1993, págs. 399 y ss., pág. 405.

${ }^{16}$ Ver N. Bobbio: El tiempo de los derechos, Madrid, Ed. Sistema, 1991, esp. págs. 13 y ss., y 63 y ss.

${ }^{17}$ «Note critiche ed autocritiche intorno alla discussione su Diritto e ragione», en L. Gianformaggio (a cura di): Op. cit., págs. 459 y ss., pág. 507. 
De esa alternativa entre el dogmatismo de una razón sustancial y el decisionismo histórico autodestructivo se puede salir considerando, como venimos haciendo con Elías Díaz, que los derechos fundamentales, fundamentadores de la democracia, tienen ellos mismos un fundamento democrático: son los requisitos necesarios de una democracia entendida como procedimiento de adopción de decisiones, de cualesquiera decisiones excepto de las que no son consistentes con ella.

Así, el fundamento de la democracia y de los derechos fundamentales es el mismo: el respeto por la autonomía de todos, el reconocimiento mutuo como seres igualmente libres para regir nuestra vida individual y colectivamente. Ernesto Garzón, refiriéndose al mismo tema, ve en la autonomía individual la justificación de lo que él denomina el «núcleo vedado» a las decisiones democráticas: la mayoría no puede impedir ni obstaculizar la autonomía de nadie, y por tanto no puede atentar contra ninguno de los medios ni de los bienes que son necesarios para su ejercicio. Ahora bien, el alcance de la autonomía de todos y cada uno de los miembros de la sociedad se equilibra mutuamente, y ese equilibrio ha de realizarse democráticamente. Por ello el blindaje de determinados derechos contra la mayoría como un «coto vedado» sólo puede ocurrir legítimamente si se considera que tales derechos son necesarios para un funcionamiento irreprochable de la democracia (funcionamiento que, como hemos dicho, presupone la autonomía del individuo y del ciudadano), pero no si con él la esfera privada queda inmune a determinadas intervenciones que precisamente pueden ser necesarias para asegurar el funcionamiento de la democracia. En caso contrario, habríamos privilegiado la autonomía del individuo a costa de la autonomía de la sociedad, o, lo que es lo mismo, a costa de la autonomía del ciudadano. Un equilibrio entre ambos es enormemente difícil y controvertible, pero sólo se puede lograr desde el punto de vista de un concepto amplio de democracia.

\section{II}

Pero ¿por qué precisamente el reconocimiento de la autonomía de todos? Si implicamos a todos estamos postulando la igualdad de los intereses de todos, o sea, la igualdad de todos para defender sus intereses como intereses generalizables (u, obviamente, para que otros los defiendan por ellos en caso de incapacidad). Tiene razón Dworkin cuando afirma que en la base del contrato que proporciona el fundamento de una sociedad justa, o sea, en la base de la posición originaria de Rawls en la que todos discuten sobre el interés general, 
se encuentra el valor de la igualdad, entendida como la igualdad de consideración y respeto que todos los seres humanos merecen como personas morales ${ }^{18}$. En un sentido análogo entiende R. Dahl el fundamento último de la democracia: el principio de la «consideración igualitaria de los intereses», que es un principio moral, juntamente con la presunción de que nadie puede ser mejor juez de ellos que uno mismo ${ }^{19}$.

Pues bien, ¿es ese imperativo de la igualdad deducible racionalmente de algún otro fundamento? Dworkin sostiene que la idea de la igualdad esencial de todos los seres humanos como personas morales es un «derecho natural», que él considera como «fundamental y axiomático» ${ }^{20}$. En Kant viene dado como un aspecto del imperativo categórico, basado en el factum de la conciencia moral. Para muchos, este imperativo categórico, que impone el reconocimiento de los demás como portadores de los mismos derechos, es hoy un postulado de la razón comunicativa. Estaría implicado, no en el factum de la conciencia, sino en el factum del lenguaje. Apel y Habermas lo entienden como una condición transcendental del acto de habla, al menos del acto del habla argumentativa ${ }^{21}$.

Ahora bien, hacer de este tipo de habla una relación universal entre todos los seres humanos es algo que ya no tiene fundamento. No es el habla misma la que me impone a mí el mandato de su utilización con los que, por ejemplo, no son de mi clase, de mi nación o de mi raza. Si no tengo necesidad de entenderme con ellos, puedo ignorarlos o instrumentalizarlos. E, inversamente, puedo ampliar los límites del lenguaje y considerar como equivalentes a los míos los intereses de aquellos con los que jamas podría tener una relación comunicativa, y dotarlos de una representación para que alguien los defienda argumentativamente. Por eso hay que darle su parte de razón a Hume, y considerar que el sentimiento o la simpatía tiene bastante que ver en la admisión de los demás como seres iguales a mí, y, por tanto, con necesidades e intereses tan relevantes como los míos.

Creo que en este límite del racionalismo está también el límite del fundamento que Elías Díaz propugna para la democracia y «sus» derechos. Elías Díaz entiende que la democracia tiene un fundamento

${ }^{18}$ Los derechos en serio, Barcelona, Ed. Ariel, 1984, págs. 234 y ss.

${ }^{19}$ La democracia y sus críticos, págs. 103 y ss., 120 y ss. Pero es el principio de la consideración igualitaria de los intereses el más importante, ya que la presunción mencionada es una regla de experiencia que admite prueba en contrario y es compatible con la representación.

${ }^{20}$ Op. cit., pág. 41 , pág. 267.

${ }^{21}$ Entre nosotros, últimamente, A. Cortina: Ética aplicada y democracia radical, Madrid, Ed. Tecnos, 1993, esp. 123 y ss. 
racional en el sentido del «racionalismo de la razón práctica», que según él no significa dogmatismo, pero que huye del escepticismo y del relativismo decisionista. Efectivamente, podemos estar de acuerdo en que es un fundamento racional en el sentido de que es consecuente con el ejercicio de la razón, que sólo puede tener lugar en el debate, en la argumentación y en la crítica. Es un fundamento no dogmático porque no impone contenidos excepto los derivados de sus propias condiciones de posibilidad. Y no es escéptico ni relativista porque reconoce como valioso aquello que permite dirimir (aunque no siempre superar) las diferencias de opiniones y creencias a través de la argumentación y de la crítica.

Pero si es verdad que un cierto grado de benevolencia, de simpatía o de compasión, es una condición necesaria para el reconocimiento mutuo, entonces hay una parte de razón en el emotivismo. No basta el razonamiento para que surja la emoción de la que depende el reconocimiento de los demás como iguales, sino que se requiere el uso persuasivo y retórico del lenguaje. La argumentación moral tiene frecuentemente esa finalidad: conmover al mismo tiempo que convencen.

También es necesario un grado de simpatía para «comprender» las razones concretas que pueden aportar los demás en apoyo de sus pretensiones, para aceptar sus necesidades como verdaderas necesidades y sus intereses como intereses generalizables. En esto tiene parte de razón, a su vez, el relativismo cultural, característico hoy de los que defienden las comunidades por encima del individuo, y que insiste en el hecho de que una forma de vida compartida es un límite a la universalidad del lenguaje. Pero sólo parte de razón. La falta de espacio obliga a poner aquí el punto final, pero no sin antes afirmar que, aunque muchos argumentos sólo pueden ser aceptados por los miembros de una comunidad, también hay otros que han de ser aceptados universalmente (supuesta la existencia del sentimiento moral de Hume), y que de hecho son aceptados por los defensores del comunitarismo en cuanto empiezan a hablar: los que abogan por la participación de todos los que tienen algo que decir en el intento de convencer (y de conmover) a los demás de la justeza de la propia posición. En esta participación universal consiste precisamente la democracia.

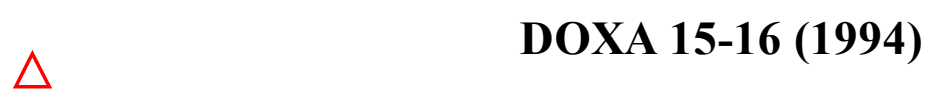

